\title{
The Relation of Dysfunctional Cognitive Schemas and Personality Dimensions in Generalized Anxiety Disorder
}

\author{
Cosmin Octavian Popa ${ }^{*}$, Adrian V. Rus², Cathleen Skinner², Zsolt S. Jakab³ \\ 1. University of Medicine and Pharmacy Tirgu Mures, Romania, Department of Ethics and Social Sciences \\ 2. Southwestern Christian University, Department of Social and Behavioral Sciences, Bethany, OK, USA \\ 3. University of Medicine and Pharmacy Tirgu Mures, Department of Counseling and Career Guidance, Romania
}

Objective: This study investigated whether differences exist in the structural personality dimensions and eighteen maladaptive cognitive schemas among in- and out-patients (Clinical Group) diagnosed with Generalized Anxiety Disorder (GAD) and people from the general population without any psychiatric diagnostic (Control Group).

Methods: The Generalized Anxiety Disorder (GAD) sample ( $N=100)$ included $35(35 \%)$ men and 65 (65\%) women, with a mean age of 36.4 years (SD = 10.86; age range 18-69). The control sample $(\mathrm{N}=100)$, included $28(28 \%)$ men and $72(72 \%)$ women, with a mean age of 27.1 years (SD = 9.8; age range 19-60). Data were simultaneously analyzed with one-way multivariate analysis of covariance (MANCOVA) to measure the effect of group membership on personality dimensions and on dysfunctional cognitive schemas, controlling for participants' age. Next, univariate analyses of covariance (ANCOVAs) were done on each item with covariate-adjusted post-hoc comparisons.

Results: The results indicate that the Clinical Group participants had unfavorable scores on all five personality dimensions (i.e., Openness, Extraversion; Conscientiousness; Agreeability; and Emotional Stability - Neuroticism) and for almost all of the dysfunctional cognitive schemas in comparison with participants in the Control Group.

Conclusions: These results have general implications in understanding Generalized Anxiety Disorder (GAD) clients and their personality characteristic's profile and dysfunctional/maladaptive cognitive schemas.

Keywords: generalized anxiety disorder, five factor model personality dimensions, maladaptive cognitive schemas, schema therapy, chronic anxiety

Received 10 October 2017 / Accepted 31 October 2017

\section{Introduction}

Generalized Anxiety Disorder (GAD) is defined by the DSM-5 as the presence of anxiety and worry for at least 6 months, especially related to events and activities in the family, professional, and/or academic area. Accordingly, these individuals find it difficult to control their preoccupation and worry (1). Knowing that GAD severely impacts social and psychological functioning (2), the present study primarily sought to investigate whether there were specific patterns of personality dimensions and maladaptive (dysfunctional) cognitive schemas in patients with GAD. Importantly, as far as we are aware, the present study is the only study that has measured the maladaptive cognitive schemas in patients with GAD with no other comorbidities (e.g., substance abuse, depression, etc.) By determining these specific patterns with the GAD profile, practitioners could improve psychological treatments for GAD. The lifetime prevalence of GAD in a USA nationally representative sample was $5.7 \%$, and prevalence for a 12 -month period was $3.1 \%$ (3). Epidemiologic studies indicate that lifetime prevalence of GAD for a 12 -month period it varies between $1.7 \%$ and $3.4 \%$ (4). Regarding pathogeny, from a neuro-cognitive point of view, it is a known fact that GAD

\footnotetext{
* Correspondence to: Cosmin Octavian Popa
} E-mail: cosmin_popa24@yahoo.com is associated with hypoactivation in the prefrontal cortex (PFC), which in turn is responsible for emotional regulation that leads to difficulties in the control of emotions, especially worry (5-6).

\section{The Five Factor Model}

The Five Factor Model (FFM) defines personality by the way a person relates to his own past life experiences and consists of five personality factors, namely Openness, Extraversion, Conscientiousness, Agreeability, and Emotional Stability Neuroticism (7-11). Out of these five personality dimensions, Extraversion and Neuroticism are predictors of anxiety and other affective/psychological disorders (1214). Further, Conscientiousness is positively correlated with Generalized Anxiety Disorder (15). However, the one personality factor that best indicates the presence of anxiety/ depression is a low level in the Emotional Stability dimension (16). Moreover, having a high level of Agreeability and a low level of Emotional Stability indicates the presence of anxiety (17).

\section{Maladaptive Cognitive Schemas}

It has been shown that maladaptive cognitive schemas (MCS) develop in early childhood, emerging from negative interpersonal interactions or relationships within various environments, such as family, school, and/or networks 
of friends. As a consequence, dysfunctional schemas will become manifest in adulthood, when the patient experiences life situations similar to those experienced during childhood (18-19). These dysfunctional cognitive schemas (see Table 1) greatly influence the way individuals think, feel, and behave in various social environments. Similarly, the CBT model explains the etiopathogenesis of GAD as being facilitated by learning processes which could explain why emotions and interpersonal relationships are a constant source of perceived danger for GAD patients (20).

\section{Objectives}

The primary aim of this study was twofold. First, this study sought to investigate whether there are differences in the structural personality dimensions, as defined by the FiveFactor Model of personality (i.e., Openness, Extraversion, Conscientiousness, Agreeability, and Emotional Stability Neuroticism) among in- and out-patients diagnosed with Generalized Anxiety Disorder (GAD) and people without any psychiatric diagnosis from the general population. The second objective of the study was to identity whether there are differences in eighteen maladaptive cognitive schemas (21) (i.e., Emotional Deprivation, Abandonment/Instability, Mistrust/Abuse, Social Isolation/Alienation, Defectiveness/Shame, Failure, Dependence/Incompetence, Vulnerability to Harm or Illness, Enmeshment/Undeveloped Self,
Entitlement/Grandiosity, Insufficient Self-Control/SelfDiscipline, Subjugation, Self-Sacrifice, Approval-Seeking/ Recognition-Seeking, Negativity/Pessimism, Emotional Inhibition, Unrelenting Standards/Hypercriticalness, and Punitiveness) among patients diagnosed with GAD and people without any psychiatric diagnosis.

\section{Methods}

\section{Compliance with Ethical Standards}

Written consent for research purposes was obtained from participants after they received the information about the study, and from appropriate Romanian authorities (Ethics Commission of Research from UMF Tirgu Mures). Participants' privacy was protected by replacing their names with identification numbers on all research documents and analyses. This study meets the clinical criteria developed by the International Conference on Harmonisation - Good Clinical Practice (22) and ethical principles and code contained in Nuremberg (23).

\section{Participants and Procedure}

The sample consisted of clinical (diagnosed with GAD) and non-clinical adult. In the combined sample $(N=200)$, the mean age at the time of interview was 31.7 years $(S D$ $=11.4$ ), ranging from 18 to 69 years. Out of 200 par-

Table 1. A Description of Each Maladaptive Cognitive Schema as Measured by the YSQ-S3 Scale adapted for Romanian Population (Young, 2005; Trip, 2006)

\begin{tabular}{|c|c|}
\hline YSQ-S3 Scale & Description \\
\hline Emotional Deprivation & $\begin{array}{l}\text { The individual thinks others are depriving him/her of the emotional support he/she needs, not offering protection and } \\
\text { understanding. }\end{array}$ \\
\hline Abandonment/Instability & $\begin{array}{l}\text { The individual's belief that other people will not be able to offer him/her emotional support due to their own instability, } \\
\text { absence, or possibility to leave them for someone else. }\end{array}$ \\
\hline Distrust/Abuse & $\begin{array}{l}\text { The subject's belief that others will eventually take advantage of him/her, intentionally deceiving or hurting, humiliating, } \\
\text { lying, or causing pain. }\end{array}$ \\
\hline Social Isolation/Alienation & $\begin{array}{l}\text { The subject's feeling of social isolation; the feeling that he/she is different from the others, thus being rejected from a } \\
\text { social group. }\end{array}$ \\
\hline Defectiveness/Shame & $\begin{array}{l}\text { A schema which refers to an inferiority complex; the subject seeing himself/herself as incapable, worthless, a bad per- } \\
\text { son, as well fearful of no longer being loved when others notice these things. }\end{array}$ \\
\hline Failure & $\begin{array}{l}\text { The subject's conviction that he/she cannot correctly perform most actions, as well as the feeling that no matter how } \\
\text { hard they try, failure in the important areas of life is certain. }\end{array}$ \\
\hline Dependence/Incompetence & $\begin{array}{l}\text { The sensation of being incapable of attaining daily goals and objectives without help and supervision from others; the } \\
\text { individual feels helpless. }\end{array}$ \\
\hline Vulnerability to Harm/IIIness & The exaggerated fear of imminent catastrophes which can occur at any time and which cannot be prevented. \\
\hline Enmeshment/Undeveloped Self & $\begin{array}{l}\text { The subject's exaggerated need to be close to relevant people in one's proximity (e.g. parents), thus involving an } \\
\text { exaggerated emotional relationship, leading to a certain degree of dependence and underdevelopment of the subject's } \\
\text { autonomy and social identity. }\end{array}$ \\
\hline Entitlement/Grandiosity & $\begin{array}{l}\text { The subject's belief that he/she is superior to others, thus deserving special rights and privileges. A disproportionate } \\
\text { sense of superiority is revealed, the goal being to gain control and power. }\end{array}$ \\
\hline Insufficient Self-Control & $\begin{array}{l}\text { Low tolerance for frustration, lack of impulse control, difficulty controlling oneself, lack of discipline in order to reach } \\
\text { certain goals, emotional instability, a disproportionate need to maintain comfort. }\end{array}$ \\
\hline Subjugation & The subject aims to gain complete control over others. \\
\hline Self-Sacrifice & $\begin{array}{l}\text { An exaggerated focus on satisfying other people's daily needs, for the purpose of avoiding being seen as selfish by oth- } \\
\text { ers, while at the same time wishing to maintain a relationship with the person the individual wishes to help. }\end{array}$ \\
\hline $\begin{array}{l}\text { Approval Seeking/ Recognition- } \\
\text { Seeking }\end{array}$ & $\begin{array}{l}\text { The subject's exaggerated need to obtain others' approval and recognition, so that one's self-esteem becomes depen- } \\
\text { dent on other people's reactions. }\end{array}$ \\
\hline Negativity/Pessimism & The subject enhances the negative and pessimistic aspects of life, minimizing the positive and optimistic ones. \\
\hline Emotional Inhibition & $\begin{array}{l}\text { The subject represses his/her actions, feelings, and spontaneous communication in order to avoid disapproval or a feel- } \\
\text { ing of shame. }\end{array}$ \\
\hline $\begin{array}{l}\text { Unrealistic Standards/ Hypercritical- } \\
\text { ness }\end{array}$ & $\begin{array}{l}\text { The subject's belief in perfectionism and completeness in reaching one's goals, based on rigid "must"-like assumptions } \\
\text { and extremely high performance standards, with the purpose of avoiding criticism }\end{array}$ \\
\hline Punitiveness & $\begin{array}{l}\text { The subject's belief that people who do not satisfy his/her own standards should be punished for their "mistakes". The } \\
\text { subject is also critical with one's own person and finds it difficult to forget the errors of others. }\end{array}$ \\
\hline
\end{tabular}


ticipants, 137 (68.5\%) were female and $63(31.5 \%)$ were male; $176(88 \%)$ were Romanian and 24 (12\%) of other ethnic origins. There were no significant differences $(\alpha=$ $.05)$ regarding gender and level of education between the subjects in our GAD and control samples. Additionally, participants in the GAD group were statistically significantly older $(M=36.40, S D=10.96)$ than their counterparts in the Control group $(M=27.05, S D=9.84), t$ $(195.75)=6.35, p<.001$.

The GAD group $(N=100)$ consisted of $35(35 \%)$ men and $65(65 \%)$ women, with a mean age of 36.4 years $(S D$ $=10.86$; age range 18-69). Of these patients, 61(61\%) had graduated from college or had postgraduate education, while the remaining 39 participants (39\%) were educated at lower levels. In addition, 80 participants in this sample $(80 \%)$ were Romanian and $20(20 \%)$ of other ethnic origins. The Control group $(N=100)$, representing a nonclinical population, was composed of $28(28 \%)$ men and $72(72 \%)$ women, with a mean age of 27.1 years $(S D=$ 9.8; age range 19-60). Within this sample, 66 participants $(66 \%)$ had graduated from college or had postgraduate education, while the remaining 34 participants (34\%) were educated at lower levels. In addition, 96 participants in this sample (96\%) were Romanian and only $4(4 \%)$ had other ethnic origins. Most of participants in this group $(68 \%)$ were enrolled in undergraduate medical courses at the University of Medicine and Pharmacy of Tirgu-Mures, Romania; and the rest of the participants had various other professions.

All participants filled out paper-pencil questionnaires (i.e., DECAS Personality Inventory - DECAS, The Young Schema Questionnaire - Short 3 - YSQ-S3) and at a later date the information was entered into electronic format. The information was collected in the Mures County Clinical Hospital (Psychiatric Clinics No. II), Mental Health Center Tirgu Mures, as well as within two private psychotherapy practices in Tirgu Mures, Romania. The inclusion and exclusion criteria were straightforward. Specifically, for the Clinical group, the inclusion criteria were the presence of Generalized Anxiety Disorder (GAD) diagnosed by a psychiatry specialist, and the exclusion criteria was the presence of (a) psychotic symptoms, (b) severe personality disorders (e.g., borderline, schizoid, paranoid according to DSM-IV), and (c) mixed personality disorders. In addition, for the Control group, the inclusion criteria were the lack of psychiatric pathology, and the exclusion criteria was the presence of (a) anxiety/depression symptoms and/ or (b) personality disorders.

\section{Measures}

All participants in the Clinical sample were diagnosed with Generalized Anxiety Disorder using structured interviews conducted by seven psychiatrists with vast experience in the field ( $M=14.5$ years), in conformity with diagnostic criteria for GAD.

\section{Questionnaire}

Personality. The DECAS Personality Inventory (24) is a psychometric evaluation instrument that has been calibrated, standardized, and validated on the Romanian population, to assess dimensional spheres of personality The internal consistency of the scales ranges from .70 to .82 , and the six weeks' test-retest stability coefficients range from .79 to .91 (25). There is good concurrent validity between the DECAS Personality Inventory and the NEO PI-R Personality Inventory (24), the levels ranging between .57 and .81 .

Maladaptive cognitive schemas: The Young Schema Questionnaire - Short 3 (YSQ-S3) is an instrument designed for measuring maladaptive cognitive schemas and it was calibrated, standardized, and validated on the Romanian population. YSQ-S3 consists of 114 items and measures 18 dysfunctional cognitive schemas; The YSQS3 subscales have a very good reliability, with Cronbach's alpha coefficients ranging from .68 to .96 , and good discriminative validity (26).

\section{Statistical Analyses}

For completing the statistical analyses, SPSS (version 19.0) and JASP (version 0.7.5.5) were used for the current research (27-28).

\section{Results}

\section{Personality}

Importantly, the demographic analyses showed that participants in the GAD group were statistically significantly older than their counterparts in the Non-Clinical group. Considering this result, for measuring the effect of group membership (Non-Clinical vs. Clinical) on all five personality dimensions as defined by the Five-Factor Model (i.e., Openness, Extraversion, Conscientiousness, Agreeableness, and Emotional Stability), and controlling for participant's age as a covariate, a one-way MANCOVA was performed. The results showed a significant multivariate main effect for group membership, Pillai's Trace $=.211$, $F(5,193)=10.29, p<.001$, but not a significant main effect for participants' age, Pillai's Trace $=.004, F(5,193)$ $=1.36, p=.984$. Significant overall MANCOVA were followed by ANCOVAs with each personality dimension as a dependent variable, group membership as an independent variable, controlling for participant's age (covariate), followed by subsequent post hoc comparisons. As shown in Table 2, these subsequent analyses revealed a significant effect $(p<.05, p<.01$, and $p<.001)$ of group membership on personality dimensions controlling for participants' age. The effect of group membership had only a marginally significant effect on Conscientiousness ( $p=.075)$, controlling for participant's age. Importantly, the covariate (participants' age) was not significantly related to any of the dependent variables (personality dimensions). 
Table 2. One-way Analyses of Covariance (ANCOVAs) for DECAS Scale Showing the Difference between Clinical and Non-Clinical Groups $(\mathrm{N}=200)$, and controlling for participant's age

\begin{tabular}{|c|c|c|c|c|c|c|c|}
\hline \multirow[b]{2}{*}{ DECAS Scale } & \multicolumn{2}{|c|}{ Non-Clinical Group } & \multicolumn{2}{|c|}{ Clinical Group } & \multirow[b]{2}{*}{$\mathrm{Fb}^{\mathrm{b}}$} & \multirow[b]{2}{*}{$\mathrm{p}$} & \multirow[b]{2}{*}{$\eta_{p}{ }^{c}$} \\
\hline & $\mathrm{M}^{\mathrm{a}}$ & SD & $\mathrm{M}^{\mathrm{a}}$ & SD & & & \\
\hline Openness & 52.43 & 9.91 & 48.00 & 11.45 & 7.06 & $<.01^{\star \star}$ & .035 \\
\hline Extraversion & 49.72 & 12.08 & 42.08 & 13.53 & 14.66 & $<.001^{\star \star \star}$ & .069 \\
\hline Conscientiousness & 48.41 & 10.39 & 45.56 & 10.12 & 3.21 & .075 & .016 \\
\hline Agreeableness & 52.45 & 8.98 & 48.89 & 9.91 & 5.87 & $.016^{\star}$ & .029 \\
\hline Emotional Stability & 48.20 & 8.84 & 39.55 & 8.19 & 42.61 & $<.001^{\star \star \star}$ & .178 \\
\hline
\end{tabular}

Note. ${ }^{*} p<.05$, two-tailed. ${ }^{* *} p<.01$, two-tailed. ${ }^{* \star \star} p<.001$, two-tailed.

a Estimated marginal means controlled for the effect of participant's age.

${ }^{\mathrm{b}}$ ANOVAs df $=1,197$ of group membership .

c Effect size (Partial Eta Squared) for differences between groups.

\section{Maladaptive Cognitive Schemas}

For measuring the effect of group membership (Non-Clinical vs. Clinical) on all 18 dysfunctional cognitive schemas, and controlling for participant's age as a covariate, a oneway MANCOVA was performed. The results showed a significant multivariate main effect for group membership, Pillai's Trace $=.966, F(18,180)=280.59, p<.001$, and for participants' age, Pillai's Trace $=.196, F(18,180)=2.43$, $p<.01$. Significant overall MANCOVA were followed by ANCOVAs for each dysfunctional cognitive schema as a dependent variable, group membership as an independent variable controlling for participant's age (covariate) followed by subsequent post hoc comparisons. These subsequent analyses revealed a significant effect $(p<.05$ and $p<.001$ ), of group membership on maladaptive cognitive schemas controlling for participants' age. Specifically, as shown in Table 3, participants in the Clinical group had significantly higher scores on 16 dysfunctional cognitive schemas but not on Emotional Inhibition and Unrealistic
Standards scales compared with their counterparts, controlling for participants' age. Importantly, the covariate (participants' age) was significantly related to dysfunctional cognitive schemas only in the case of Distrust/Abuse; Social Isolation/Alienation; Entitlement/Grandiosity; SelfSacrifice; and Emotional Inhibition.

\section{Discussion}

As hypothesized, the results of the present study indicate that participants in the Clinical group (i.e., patients diagnosed with GAD with no comorbidities) had a higher level of unfavorable scores on all five dimensions of personality (i.e., Openness, Extraversion, Conscientiousness, Agreeability, and Emotional Stability - Neuroticism) than participants without any psychiatric diagnosis, controlling for participants' age. In addition, the results also showed that participants in the Clinical group had a higher level of unfavorable scores on all dysfunctional cognitive schemas except Emotional Inhibition and Unrealistic Standards

Table 3. One-way Analyses of Covariance (ANCOVAs) for YSQ-S3 Scale Showing the Difference between Clinical and Non-Clinical Groups $(\mathrm{N}=200)$, and controlling for participant's age

\begin{tabular}{|c|c|c|c|c|c|c|c|}
\hline \multirow[b]{2}{*}{ YSQ-S3 Scale } & \multicolumn{2}{|c|}{ Non-Clinical Group } & \multicolumn{2}{|c|}{ Clinical Group } & \multirow[b]{2}{*}{$\mathrm{Fb}^{\mathrm{b}}$} & \multirow[b]{2}{*}{$\mathrm{p}$} & \multirow[b]{2}{*}{$\eta_{p}{ }^{c}$} \\
\hline & $M^{a}$ & SD & $M^{a}$ & SD & & & \\
\hline Emotional Deprivation & 11.80 & 5.12 & 21.04 & 3.13 & 196.07 & $<.001^{\star \star \star}$ & .499 \\
\hline Abandonment/Instability & 13.14 & 5.37 & 22.92 & 2.21 & 234.06 & $<.001^{\star \star \star}$ & .543 \\
\hline Distrust/Abuse ${ }^{\dagger}$ & 14.41 & 5.23 & 23.50 & 2.93 & 198.69 & $<.001^{\star \star \star}$ & .502 \\
\hline Social Isolation/Alienation ${ }^{\dagger}$ & 14.01 & 4.75 & 15.71 & 4.27 & 5.97 & $<.05^{\star}$ & .029 \\
\hline Defectiveness/Shame & 8.48 & 4.21 & 16.84 & 3.23 & 205.91 & $<.001^{\star \star \star}$ & .511 \\
\hline Failure & 12.78 & 5.71 & 18.73 & 3.05 & 70.50 & $<.001^{\star \star \star}$ & .264 \\
\hline Dependence/Incompetence & 13.73 & 5.42 & 18.14 & 3.32 & 39.95 & $<.001^{\star \star \star}$ & .169 \\
\hline Vulnerability to Harm/Illness & 10.34 & 4.20 & 18.48 & 2.28 & 240.54 & $<.001^{\star \star \star}$ & .550 \\
\hline Enmeshment & 10.71 & 4.89 & 18.07 & 3.75 & 117.99 & $<.001^{\star \star \star}$ & .375 \\
\hline Entitlement/Grandiosity ${ }^{\dagger}$ & 10.10 & 5.16 & 21.44 & 2.27 & 368.94 & $<.001^{\star \star \star}$ & .652 \\
\hline Insufficient Self-Control & 15.18 & 7.09 & 20.14 & 2.67 & 36.01 & $<.001^{\star \star \star}$ & .175 \\
\hline Subjugation & 12.61 & 5.18 & 18.96 & 2.54 & 101.84 & $<.001^{\star \star \star}$ & .341 \\
\hline Self-Sacrifice $^{\dagger}$ & 14.25 & 6.20 & 19.46 & 4.08 & 42.74 & $<.001^{\star \star \star}$ & .178 \\
\hline Approval Seeking & 29.92 & 9.39 & 58.10 & 12.48 & 271.61 & $<.001^{\star \star \star}$ & .580 \\
\hline Negativity/Pessimism & 14.00 & 6.05 & 46.35 & 5.79 & 1237.09 & $<.001^{\star \star \star}$ & .863 \\
\hline Emotional Inhibition ${ }^{\dagger}$ & 33.51 & 13.16 & 21.36 & 3.16 & 70.68 & $<.001^{\star \star \star}$ & .264 \\
\hline Unrealistic Standards & 30.84 & 9.42 & 20.41 & 2.39 & 95.87 & $<.001^{\star \star \star}$ & .327 \\
\hline Punitiveness & 38.39 & 11.29 & 59.54 & 8.03 & 193.45 & $<.001^{\star \star \star}$ & .495 \\
\hline
\end{tabular}

Note. ${ }^{*}<.05,{ }^{\star \star \star} p<.001$, two-tailed.

a Estimated marginal means controlled for the effect of participant's age.

b ANOVAs df $=1,197$ of group membership.

c Effect size (Partial Eta Squared) for differences between groups. †For this item, the participant's age also had a statistically significant effect. 
when compared with participants in the Control group (non-clinical participants).

Specifically, (see Table 2) our study revealed that patients with GAD showed statistically significantly lower scores on Openness $(M=48.00)$, Extraversion $(M=42.08)$, Conscientiousness ( $M=45.56)$, Agreeableness $(M=48.89)$, and Emotional Stability $(M=39.55$; or high Neuroticism), controlling for participants' age, compared with their counterparts in the Control group. In the case of Conscientiousness $(M=45.56)$, the difference was only marginally significant. This pattern of results is consistent with other studies which found low scores on these dimensions of personality in clinical samples. Specifically, these studies not only showed low scores on Extraversion, Conscientiousness, and Emotional Stability (high Neuroticism), but also they revealed a relationship between these personality dimensions and the presence of anxiety and depression symptomatology (29-30). Not only are the aforementioned low scores of these personality dimensions associated with anxiety and depression symptomatology, but along with low Agreeableness, these four characteristics are typically associated with almost all types of symptoms of clinical disorders (31). Furthermore, in the case of GAD patients, a general personality profile highlights the presence of low Extraversion and Emotional Stability represented by various psycho-behavioral patterns such as shyness, lack of social enthusiasm, avoidance to take on leadership roles, emotional repression, social inhibitions, distress, feelings of hopelessness and helplessness, as well as pessimism (17). Our results suggest that the chronic nature of GAD could be attributed to personality because the dimensional structure of personality is stable, with certain alterations occurring over time only at the surface level (11). Also, high Neuroticism plays an important role in the occurrence and persistence of the specific worrying symptoms of GAD, even if the two (Neuroticism and GAD) are different clinical entities (32). In addition, low scores of Agreeability and Emotional Stability were also found in a non-clinical sample of undergraduate students (33), where these two personality dimensions were also associated with maladaptive cognitive schemas, supporting the assumption that, in general, personality dimension can be seen as a predictor of these dysfunctional patterns of thinking.

In our study, out of the 18 maladaptive cognitive schemas (MCS/dysfunctional schema), 16 were statistically significantly higher (unfavorable) for patients with GAD compared with participants with no psychiatric pathology, controlling for participants' age (see Table 3). Two schemas were an exception, occurring at a higher level in the patients with no psychiatric pathology, namely the Emotional Inhibition and the Unrealistic Standards schemas. Specifically, the MCS which occurred at the highest levels in GAD patients were Emotional Deprivation $(M=21.04)$, Abandonment/Instability $(M=22.92)$, Approval Seeking $(M$ $=58.10)$, Negativity/Pessimism $(M=46.35)$, and Punitiveness $(M=59.54)$. Generally, in the case of GAD patients, these MCS are responsible for a dysfunctional thinking pattern. For example, Emotional Deprivation is often exhibited as a dysfunctional thinking pattern where an individual with GAD worries about the likelihood of loved ones being unable to offer the emotional support and safety they need. Moreover, there are cognitive distortions generated by the Abandonment/Instability schema, which causes feelings of intolerance to uncertainty, characterized by the fear of being deserted for another person or by worry related to the fact that emotional support from a loved one in a time of need might not be received. In this context, the Approval Seeking schema generates a relationship with the world and those around the individual that is formed by way of feedback received from the people around him or her, so that self-esteem becomes dependent on the reaction of others. Punitiveness is responsible for a critical perception of one's own person as well as of those around him or her, so that errors committed by others, or by oneself, are forgotten with difficulty.

MCS are not only associated with GAD, but also are related with anxiety/depression disorders, and the presence of these schemas can also indicate comorbidities with various personality disorders or substance abuse (34). Furthermore, there are specific MCS associated with each personality pathology (35). We know that GAD is strongly associated with personality disorders (36), and from a clinical and comorbidity point of view, GAD is also similar to emotional disorders, namely depression (18). For instance, regarding depressive symptoms, an association has been found between high Neuroticism and low Extraversion, and the presence of MCS (37). Two schemas are mainly involved here, namely Emotional Deprivation and Abandonment/Instability (38). Interestingly, these two schemas are similar both in GAD patients and depressive patients; and it would be interesting to find out in future studies whether both GAD and depressive patients present common dysfunctional cognitive schemas.

\section{Conclusions}

The results of this study have general implications regarding our understanding of GAD clients and their personality profile characteristics and maladaptive cognitive schemas. Additionally, these results encourage us to believe that cognitive-behavioral therapy (CBT) intervention for GAD patients could be adapted to target the specific symptomatology of this disorder such as (a) the maladaptive cognitive schemas that play a role in the chronic nature of GAD, and (b) the disharmonic dimensional structure of these patients' specific personalities.

The intensity and severity of MCS in anxiety disorders or chronic psychological conditions (including GAD) may indicate the use of a complex psychotherapeutic approach such as Schema Therapy (ST). This is due to the fact that patients with high MCS scores present a primary diagnosis of anxiety disorder, which can co-occur with personality disorders or organic illnesses. Specifically, ST is 
a therapeutic direction focused on persistent or chronic psychological issues and may be appropriate in the context of GAD (39). Furthermore, treating GAD through Metacognitive Therapy (MCT) can also be a viable treatment option, based on the results presented in this study. For this purpose, however, the conceptualization of the MCSbased model (specific to ST) should be transitioned to a more MCT specific model. Moreover, an integrative approach of CBT, combining multiple techniques or orientations (i.e., Rational Emotive Behavior Therapy, Cognitive Therapy, Schema Therapy or Metacognitive Therapy, and Mindfulness) can also be a good therapeutic approach for GAD (20).

Thus, future studies should investigate the impact of treatment, comparing Schema Therapy with antidepressant medication in treating GAD. It would be interesting to determine whether the efficiency of a direct approach to MCS's through Schema Therapy is superior, equal, or inferior to antidepressant medication. Based on the present study, a specific therapeutic plan for treating GAD could be created, tested, and empirically validated using the findings from this study.

\section{Limitations}

Non-probability sampling techniques were used in selecting the participants of the current study, and, consequently, caution is necessary when interpreting and generalizing the outcomes of this convenience sample study. Furthermore, the self-reported measures (i.e., DECAS Personality Inventory and Young Schema Questionnaire - Short 3) could have been influenced by social desirability bias or the presence of psychopathologic symptomatology. In addition, the present study only investigated the differences between clinical and non-clinical groups across variables for personality characteristics and maladaptive cognitive schemas, and, therefore, no causal relationship can be assumed. Additionally, the significant effect of participants' age on five schemas (i.e., Distrust/Abuse; Social Isolation/ Alienation; Entitlement/Grandiosity; Self-Sacrifice, and Emotional Inhibition) should be taken into account when results are interpreted. Future studies (with a more diverse sample in respect to age) are needed to elucidate the nature of this relationship.

\section{Conflict of interest}

None to declare.

\section{Reference}

1. American Psycyatric Association - Diagnostic and Statistical Manual of Mental Disorders, Fifth Edition (DSM-5). American Psychiatric Association. Wasington, D.C., 2013, 222-226.

2. Mendlowicz M, Stein M - Quality of life in individuals with anxiety disorders. Am J Psychiatry. 2000 May; 157:669-682.

3. Kessler R, Berglund P, Demler O, et al - Lifetime Prevalence and Ageof-Onset Distributions of DSM-IV Disorders in the National Comorbidity Survey Replication. Arch Gen Psychiatry. 2005 Jun;62:593-602.

4. Wittchen HU, Jacobi F, Rehm J, et al - The size and burden of mental disorders and other disorders of the brain in Europe 2010. J Psychopharmacol. 2013 Sep;2:655-679.

5. Salters-Pedneault K, Roemer L, Tull MT, et al - Evidence of broad deficits in emotion regulation associated with chronic worry and generalized anxiety disorder. Cogn Ther Res. 2006 Aug;30: 469-480.

6. Ball TM, Ramsawh HJ, Campbell-Sills L, et al - Prefrontal dysfunction during emotion regulation in generalized anxiety and panic disorders. Psychol Med. 2013 Jul;43:1475-1486.

7. McCrae R, John $\mathrm{O}$ - An introduction to the five-factor model and its applications. J of Person. 1992 Jun;60;175-215.

8. McCrae R, Costa P - Personality trait structure as a human universal. Am Psychol. 1997 May; 52:509-516.

9. Terracciano A, McCrae RR, Brant LJ, et al - Hierarchical Linear Modeling Analyses of NEO-PI-R Scales In the Baltimore Longitudinal Study of Aging. Psychology and aging. 2005 Sep;20:493-506.

10. McCrae R, Costa PT - Personality in adulthood: A five-factor theory perspective. Guilford Press, New York, NY, 2003.

11. McCrae R, Costa, PJ - The five-factor theory of personality. in John OP, Robins WR, Pervin L (eds): Handbook of personality: Theory and research. The Guilford Press. New York, NY, 2008, 176.

12. Zinbarg RE, Uliaszek AA, Adler JM - The role of personality in psychotherapy for anxiety and depression. J of Person. 2008 Dec;76:1649-1688.

13. Tang TZ, DeRubeis RJ, Hollon SD, et al - Personality change during depression treatment: a placebo-controlled trial. Arch Gen Psychiatry. 2009 Dec;66:1322-1330.

14. Karsten J, Penninx B, Riese H, et al - The state effect of depressive and anxiety disorders on big five personality traits. J Psychiatr Res. 2012 May;46:644-650.

15. Rosellini AJ, Brown TA - The NEO five-factor inventory: latent structure and relationships with dimensions of anxiety and depressive disorders in a large clinical sample. Assessment, 2011 Mar;18:27-38.

16. Consortium of Genetics and Personality - Meta-analysis of genomewide association studies for neuroticism, and the polygenic association with major depressive disorder. JAMA Psychiatry. 2015 Jul;72:642-650.

17. Popa OC, Nireștean A, Ardelean M, et al - Community mental health service - The treatment of anxiety and its effects from the point of view of the association of personality dimension. RCIS. 2013 Dec;43:49-60.

18. Beck AT, Clark DA - Cognitive therapy of anxiety disorders. Guilford Press. New York, NY, 2010.

19. Young J, Klosko J, Weishaar M - Schema therapy: A practitioner's guide. The Guilford Press, New York, NY, 2003.

20. Rapgay L, Bystritsky A, Dafter RE, et al - New strategies for combining mindfulness with integrative cognitive behavioral therapy for the treatment of generalized anxiety disorder. J Ration Emot Cogn Behav Ther. 2011 Jun;29:92-119.

21. Young JE - Young Schema Questionnaire - Short Form 3 (YSQ-S3). Cognitive Therapy Center. New York, NY, 2005.

22. Dixon J - International Conference on Harmonization Good Clinical Practice. Qual Assur. 1999 Apr-Jun;6:65-74.

23. U.S. Department of Health \& Human Services. 2015. Retrieved from HHS.gov: http://www.hhs.gov/ohrp/archive/nurcode.html

24. Sava FA - Inventarul de personalitate DECAS. Manualul utilizatorului. ArtPress. Timisoara, 2008.

25. Sava FA, Popa RI - Personality types based on the big five model: A cluster analysis over the Romanian population. Cogn Brain Behav. 2011 Jun;15:359-384.

26. Trip S - The Romanian version of Young Schema Questionnaire-short form 3 (YSQ-S3). JEBP. 2006 Jun;6173-181.

27. Love J. et al. JASP (Version 0.7.5) [Computer software]. 2015. Retrieved from https://jasp-stats.org/download/

28. IBM Corp. IBM SPSS Statistics for Windows (Version 19.0). Armonk. NY: IBM Corp, 2010.

29. Kotov R, Gamez W, Schmidt F, et al - Linking "big" personality traits to anxiety, depressive, and substance use disorders: A meta-analysis. Psychol Bull. 2010 Sep;136:768-821.

30. Uliaszek AA, Zinbarg RE, Mineka S, et al - The role of neuroticism and extraversion in the stress-anxiety and stress-depression relationships. Anxiety Stress Coping. 2010 Jul;23:363-381.

31. Malouff J, Thorsteinsson E, Schutte N - The relationship between the five-factor model of personality and symptoms of clinical disorders:A Meta-analysis. J Psychopathol Behav Assess. 2005 Jun;27:101-114.

32. Hale WW, Klimstra TA, Meeus WHJ - Is the generalized anxiety disorder symptom of worry just another form of neuroticism? A 5-year longitudinal study of adolescents from the general population. J Clin 
Psychiatry. 2010 May; 71:942-948.

33. Sava F - Maladaptive schemas, irrational beliefs, and their relationship with the five factor personality model. JCBP. 2009 Jun;9:135-147.

34. Shorey R, Elmquist J, Anderson S, et al - The relationship between early maladaptive schemas, depression, and generalized anxiety among adults seeking residential treatment for substance use disorders. J Psychoactive Drugs. 2015 Jul-Aug;47(3):230-238.

35. Thimm JC - Incremental validity of maladaptive schemas over five-factor model facets in the prediction of personality disorder symptoms. J. Behav. Ther. \& Exp. Psychiat. 2011 Sep;50:777-782

36. Dilbaz N, Cavus SY, Darcin AE - Treatment resistant generalized anxiety disorder. in: Selek S (eds): Different views of anxiety disorders. InTech. Rijeka, CR, 2011, 219-232.

37. Thimm JC - Personality and early maladaptive schemas: a five-factor model perspective. J Behav Ther Exp Psychiatry. 2010b Dec;41:373380.

38. Renner F, Lobbestael J, Peeters F, et al - Early maladaptive schemas in depressed patients: Stability and relation with depressive symptoms over the course of treatment. J Affect Disord. 2012 Feb;136:581-590.

39. Hawke L, Provencher M - Early maladaptive schemas: Relationship with case complexity in mood and anxiety disorders. J Cogn Psychother. 2013 Dec;27:359-369. 